\title{
EFFECT OF AGEING ON HEMP WASTE/POLYETHYLENE COMPOSITES SURFACE PROPERTIES
}

\author{
Zane Zelca, Silvija Kukle, Janis Kajaks, Ieva Bake \\ Riga Technical University, Latvia \\ gusare@inbox.lv, silvija.kukle@rtu.lv,janis.kajaks@rtu.lv, ieva.bake@edu.rtu.lv
}

\begin{abstract}
The research focuses on $40 \mathrm{wt} \%$ hemp reinforced polyethylene (LLDPE) aged composite surface properties. The increased use of natural components-reinforced composites in an outdoor environment has led to questions concerning the environmental durability of these materials. As a reinforcing component chemically modified hemp first processing waste was used. The waste was treated with alkali, silanized and the surface was modified with a sol-gel method. For some composites the additives have been added during the manufacturing process. UV ageing was performed according to the standard ASTM G154. UV radiation has a crucial influence on the physical properties and visual changes of the polyethylene matrix. The composite samples have become brighter and micro-hardness has decreased, cracks and cavities on the surface of the composite were observed after ageing.
\end{abstract}

Keywords: composite ageing, surface micro-hardness, hemp waste, polyethylene.

\section{Introduction}

Polymer/natural fibre composites have been used in many applications, like automotive parts, household goods, furniture and others. The use of natural fibres for reinforcement of composites reduces the consumption of polymer and density of the material [1]. Aging of composite materials is affected by the nature of each component, but combining components into one material makes it even more difficult to predict the aging process [2].

Polymer degradation is influenced by one or more environmental factors, such as temperature, UV radiation, or chemical reactions. Changes of the tensile strength, discoloration or change of the shape can be detected [3].

Aging of hemp fibres under the influence of temperature and UV is mainly indicated by a change in colour and a decrease in mechanical properties due to lignin photodegradation. Not only the environmental impact, but also the method of composite production and pre-treatment of components play an important role [4]. The processing temperature and aggressive chemical pre-treatment can contribute to aging of hemp. The hemp treatment can improve the adhesion between the fibres and the matrices [2]. The alkali treatment on oil palm empty fruit bunches enhanced the tensile strength and thermal stability of the fibre samples [5]. Other chemical pre-treatment methods that improve the properties of natural polymers and composites have also been reported in literature, like silanization, acetylation, peroxide treatment and others [2].

Ageing of polymer/natural fibre composites occurs due to environmental factors, such as UV radiation, water, oxygen and temperature. As the temperature increases, the volume of the material changes, as a result the internal tensions increase weakening the material strength. The chemical reactions in the open air, diffusion and solubility of the ageing products also accelerate ageing of the composite materials. The lack of covalent bonds in macromolecules under the influence of UV radiation produces free radicals [6], which contribute to deeper ageing of the materials. Oxygen also promotes oxidation of materials and is a suitable environment for various living organisms. The presence of water promotes hydrolysis, hydration and capillary forces, which destroy the material by penetrating its deeper layers [7]. Natural fibre composites used outdoors are subject to radiation and covalent bonds break in the organic polymer resulting in colour fading, surface roughening, mechanical properties decrease notably in humid environments [8]. UV has played a significant role in degrading the material strength. The natural fibre tensile strength was found to decrease with duration of the UV exposure time [2]. Chemical treatment with maleic anhydride polypropylene was given to sisal fibre, after exposure to UV radiation in a weatherometer the tensile properties of both untreated and chemically treated composites were observed to have decreased due to chain scission - the maleic anhydride polypropylene treated fibres composite has a lower retention in tensile strength than untreated samples [9]. 
These processes can be modelled in a similar way as those occurring in nature by accelerated ageing in an artificial climate chamber. The influence of using accelerated UV equipment is also contributing to the degradation rate, where it degrades much faster than the normal UV exposure [2]. The research focuses on changes of the properties (surface micro-hardness and surface quality) of aged composites. Changes in the surface quality and hardness allow to predict the possible changes in the mechanical properties and understand whether they need to be measured or not. To save time and resources, it is important to evaluate the composite surface before using destructive test methods.

\section{Materials and methods}

Linear low density polyethylene (LLDPE) LL6201 XR grade was used as a polymer matrix and as reinforcement hemp waste was used. The lignocellulose-containing reinforcing component - the Bialobrzeskie variety hemp stem first processing waste (A) was collected in Latvia. Initially reinforcing components were grinded by a $1 \mathrm{~cm}$ mesh sieve, then treated according to the selected chemical treatment and milled a second time with a $1 \mathrm{~mm}$ mesh sieve in the RETSCH ZM-200 mill, with the rotor speed of $1800 \mathrm{rpm}$. Grinding after chemical treatment was necessary to remove clumped waste particles. Ten composite variants were manufactured applying different waste chemical treatments and additives. The chemical pre-treatments used to treat hemp waste have been chosen to take into account the concentrations found in the literature [10] and the compositions optimized in previous studies [12].

The following chemical waste treatments were used.

Treatment with alkali - Hemp particles were treated with 0.0025 or $0.05 \mathrm{~mol}$ of $\mathrm{NaOH}$ and distilled water solution for 30 minutes at $20{ }^{\circ} \mathrm{C}$, then rinsed in distilled water to neutral $\mathrm{pH}$.

Silanization - To $80 \%$ ethyl alcohol solution 2 mol of silane (TEOS or APTES) was added. The hydrochloric acid was added until $\mathrm{pH} 4$ was reached. Waste was soaked for $1 \mathrm{~h}$ in the prepared solution (sil), then dried in a thermal oven for $24 \mathrm{~h}$ at $60{ }^{\circ} \mathrm{C}$, and then held in a vacuum oven for $2 \mathrm{~h}$ at $110^{\circ} \mathrm{C}(1 \mathrm{bar})$.

Sol-gel synthesis - The sol was synthesized according to the planned combinations using the selected silane as a precursor (APTES - (3-Aminopropyl) triethoxysilane or TEOS - Tetraethyl orthosilicate). Water and / or ethyl alcohol were added to the hydrolysis and condensation processes, the chosen acid ( $\mathrm{HCl}$ or $\mathrm{HF}$ ) serves as a catalyst for adjusting the environmental acidity to the required $\mathrm{pH}$. Zinc acetate dihydrate (ZAD) has also been added as a modifier in some combination of sols, see Table 1. The reinforcing components are soaked in the sol to ensure even coverage. The following sol combinations were assigned according to the following principle: silane mol:catalyst mol:modifier $\mathrm{mol} / \mathrm{pH}$.

Table 1

Sol components, synthesis and waste processing parameters

\begin{tabular}{|c|c|c|c|c|c|}
\hline \multirow{2}{*}{ Sol variant } & \multicolumn{2}{|c|}{ Mixing the sol } & \multirow{2}{*}{$\frac{\text { Drying the waste }}{{ }^{\circ} \mathrm{C}}$} & \multicolumn{2}{|c|}{ Heating the waste } \\
\hline & ${ }^{\circ} \mathrm{C}$ & $\min$ & & ${ }^{\circ} \mathrm{C}$ & $\min$ \\
\hline TEOS 0.14:HF $1.6 / 2$ & 50 & 10 & 00 & 118 & 10 \\
\hline TEOS 0.09:HF 0.5:ZAD 7.5/5.5 & JU & 40 & 90 & $1 \angle 0$ & 10 \\
\hline APTES 0.06: $\mathrm{HCl} 0.23 / 4.5$ & 23 & 72 & 60 & 110 & 5 \\
\hline APTES 0.06: $\mathrm{HCl} 0.23 / \mathrm{ZAD} 7.5 / 6.5$ & 23 & $1 / 20$ & 60 & 110 & 5 \\
\hline
\end{tabular}

The reinforcing components were dried at $60^{\circ} \mathrm{C}$ for $12 \mathrm{~h}$ before introduced into the composite to minimize the amount of moisture from uncoupled water and to prevent air intake during pressing. The composites were made with a heated two-roller mill (V), see Table 2, (rollers temperature 145 and $150^{\circ} \mathrm{C}$ for 10 minutes).

Part of the samples were modified with maleinised polyethylene wax (MAPE) $2 \mathrm{wt} \%$ of PRIEX 15005 MAPE granules and 2 wt $\%$ by weight of zinc oxide nanoparticles $(\mathrm{ZnO})$, see Table 2. Composite modifiers were added into the rolling process by calculating their percentage of the matrix weight. After mixing by the two roller mill the materials were cut in a knife mill to obtain irregularly shaped granules. The granules were pressed at $150^{\circ} \mathrm{C}$ with $5 \mathrm{MPa}$ pressure to obtain plates for further testing. 
To evaluate the kinetics of the ageing process of film-type composites, the samples were aged in a UV chamber (model Q-UV spray with solar Eye Irradiance control) equipped with a UVA-340 radiation lamp (wavelength region from $365 \mathrm{~nm}$ down to the solar cut-off $295 \mathrm{~nm}$ ), performed according to ASTM G 154 [11]. Duration of one cycle was $12 \mathrm{~h}$, total length of the ageing process $1000 \mathrm{~h}$. After ageing, changes in the sample surface micro-hardness comparison with the relevant nonaged samples were determined.

Samples of composites are marked by the following principle: Reinforcing component wt \%/(reinforcing component processing)/manufacturing method/matrix modifier in manufacturing process wt \%.

Table 2

Composite variants, waste pre-treatment and composite additives

\begin{tabular}{|l|c|c|c|c|c|}
\hline \multirow{2}{*}{ Sample } & \multicolumn{2}{c|}{ Waste pre-processing } & \multicolumn{2}{c|}{$\begin{array}{c}\text { Additives in } \\
\text { composites processing }\end{array}$} \\
\cline { 2 - 6 } & Silanized & Alcaline & Sol-gel & MAPE & $\mathrm{ZnO}$ \\
\hline A40/-/V/- & & & & & \\
\hline A40/(NaOH 0.05)/V/- & & $\mathrm{x}$ & & & \\
\hline A40/(NaOH 0.05)/V/ZnO & & $\mathrm{x}$ & & & $\mathrm{x}$ \\
\hline A40/-/V/MAPE 2 & & $\mathrm{x}$ & $\mathrm{x}$ & & \\
\hline A40/(NaOH 0.05 \& TEOS 0.14:HF 1.6/2)/V/- & & $\mathrm{x}$ & $\mathrm{x}$ & & \\
\hline A40/(NaOH 0.05 \& TEOS 0.09:HF 0.8:ZAD & & $\mathrm{x}$ & & & \\
7.5/5.5/V/- & $\mathrm{x}$ & $\mathrm{x}$ & & & \\
\hline A40/(NaOH 0.05 \& sil APTES 2)/V/- & & & $\mathrm{x}$ & & \\
\hline A40/(NaOH 0.05 \& sil TEOS 2)/V/- & & & $\mathrm{x}$ & & \\
\hline A40/(APTES 0.06:HCl 0.23/4.5)/V/- & & & \\
\hline A40/(APTES 0.06:HCl 0.23:ZAD 7.5/6.5)/V/- & &
\end{tabular}

The micro-hardness (HV) of the sample surfaces (by Vickers M-41) was determined by pressing a regular square diamond pyramid with a $136^{\circ}$ angle between the faces on the sample surface. For determination of the micro-hardness, $1 \mathrm{~mm}$ thick pressed flat and smooth composite sheets with the lowest possible surface roughness were used. According to the standard ASTM E384, the applied load was $200 \mathrm{~g}$ [12].

For investigation of the cross-sectional fracture plane of the composite samples, micrographs were taken with scanning electron and optical microscopes. The cross-section of each sample was measured by an optical microscope at 15 places to determine the depth of the aged layer; the relative error did not exceed $6 \%$.

\section{Results and discussion}

\section{Surface micro-hardness}

The micro-hardness of the composite surface, after aging, rapidly decreased, the composite hardness decreased between 31 and $62 \%$, see Table 3 . The fastest loss of surface micro-hardness was for both composites with alkali pre-treatment of waste and subsequent silanization (A40/(NaOH 0.05 $\&$ sil APTES 2)/V/-; A40/(NaOH $0.05 \&$ sil TEOS 2)/V/-) at 62 and $55 \%$. Similar changes in the surface micro-hardness were for the untreated waste containing composite, APTES-containing sol treated, and TEOS sol modified with ZAD waste composite (A40/-/V/-; A40/ (APTES 0.06:HCl 0.23/4.5)/V/-; A40/(NaOH 0.05 \& TEOS 0.09:HF 0.8:ZAD 7.5/5.5)/V/-) samples, see Table 3.

The lowest micro-hardness loss $(31 \%)$ was observed for A40/(NaOH $0.05 \&$ TEOS 0.14:HF 1.6/2)/V/- sample. The composites (A40/(NaOH 0.05)/V/-, A40/(NaOH 0.05)/V/ZnO, A40/-/V/MAPE 2) hardness decreased between 34 and $38 \%$. The surface of the aged specimens was no longer as smooth as the non-aged samples, so the surface micro-hardness may be determined with greater inaccuracy. Only one of the five measurements was usable, because the imprinted traces of the pyramid were practically invisible on the light surface. 
Composite surface micro-hardness

Table 3

\begin{tabular}{|l|c|c|c|}
\hline \multicolumn{1}{|c|}{ Sample } & Unaged, MPa & Aged, MPa & Decrease \\
\hline A40/-/V/- & 80.1 & 41.4 & $48 \%$ \\
\hline A40/(NaOH 0.05)/V/- & 78.6 & 50.6 & $36 \%$ \\
\hline A40/(NaOH 0.05)/V/ZnO & 95.3 & 63 & $34 \%$ \\
\hline $\begin{array}{l}\text { A40/(NaOH 0.05 \& TEOS 0.09 :HF 0.8:ZAD } \\
\text { 7.5/5.5)/V/- }\end{array}$ & 79.4 & 37.7 & $52 \%$ \\
\hline A40/(NaOH 0.05 \& TEOS 0.14:HF 1.6/2)/V/- & 77.9 & 53.7 & $31 \%$ \\
\hline A40/(NaOH 0.05 \& sil TEOS 2)/V/- & 93.6 & 41.9 & $55 \%$ \\
\hline A40/(NaOH 0.05 \& sil APTES 2)/V/- & 77.2 & 29.4 & $62 \%$ \\
\hline A40/(APTES 0.06:HCl 0.23/4.5)/V/- & 85.1 & 42.8 & $50 \%$ \\
\hline A40/(APTES 0.06:HCl 0.23/ZAD 7.5 /6.5)/V/- & 80 & 41.2 & $49 \%$ \\
\hline A40/-/V/MAPE 2 & 87.7 & 54.3 & $38 \%$ \\
\hline
\end{tabular}

\section{Surface structure of composites after aging}

The samples treated in the ageing chamber were analysed to predict the obtained environmental impact of the samples obtained. It can be seen that the surface structure has become rough, suggesting that erosion of surface has started. The fastest ageing of the surface layer has occurred due to faster temperature fluctuations, higher radiation intensity and aggressive agent concentration.

The alkali-treated waste composite was similar to the untreated waste composite after ageing (Fig. 1 and 3), the surface had cracks, reinforcing components were exposed. The addition of $\mathrm{ZnO}$ nanoparticles has reduced the smooth structure of the composite surface (Fig. 2), but cracks and exposed hemp waste were also clearly visible.

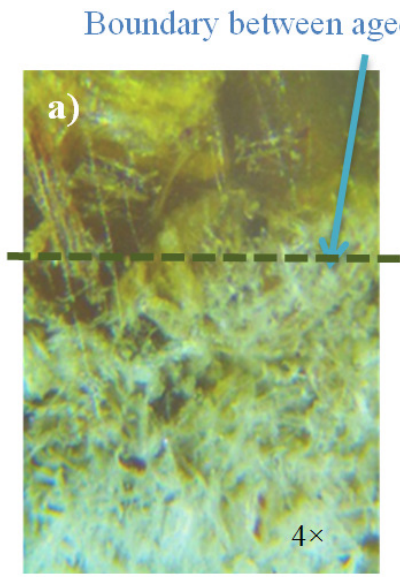

Fig. 1. Surface of LLDPE composites reinforced with untreated waste: a) border between aged and non-aged surface [13], b) aged surface

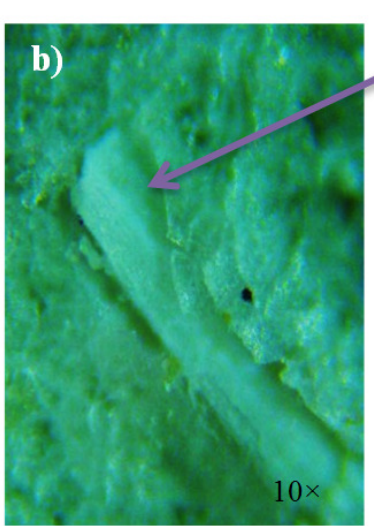

\section{Fig. 2. A40/(NaOH 0.05)/V/ZnO surface after ageing [13]}

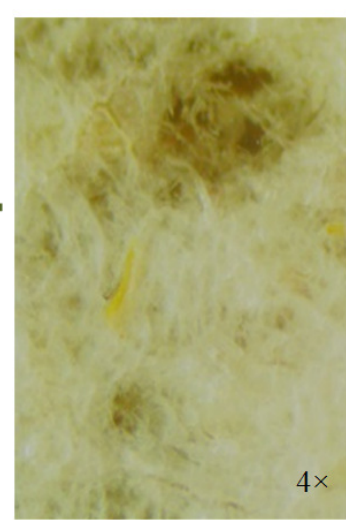

Fig. 3. A40/(NaOH 0.05)/V/- surface after ageing

The surface of the sample A40/(NaOH 0.05 \& TEOS 0.14:HF 1.6/2)/V/- after ageing differs from the other samples (Fig. 4), it was highly cracked, flaky, exposed portions and flakes were easily detached due to more rapid erosion comparing with the other samples. It can be seen that the pretreatment of waste also influenced the properties of the matrix. The aggressive environment facilitates water penetration deeper into the composite through cracks and exposed channels, gradually leading to a decrease of the composite strength.

As a result of ageing, the samples A40/(NaOH 0.05 \& TEOS 0.09:HF 0.8:ZAD 7.5/5.5)/V/- and A40/(APTES 0.06: $\mathrm{HCl}$ 0.23/4.5)/V/- exposed cavities originally formed by air inclusions (Fig. 5). Moisture can easily enter and accumulate in these cavities, and capillary forces contribute to faster deterioration of the composite in the deeper layers. The aged composite with MAPE additive looks 
damaged, deep cracks visible on the surface. Hemp particles were protruding through the surface, matrix flaky and wide cracks on the composite $\mathrm{A} 40 /(\mathrm{NaOH} 0.05 \&$ sil TEOS 2)/V/- were observed.

Comparing all the obtained composite images, the structure of the aged surface looks similar, except for the composite A40/(NaOH $0.05 \&$ TEOS $0.14: \mathrm{HF} 1.6 / 2) / \mathrm{V} /$ - the surface has pronounced cracks (Fig. 4), the flakes were easily detached by touching from the surface, and it was not possible to determine the depth of the damaged surface, so it is necessary to examine at the cross-sections of the composites and evaluate the depth of the layer that changed colour, brightness and structure.

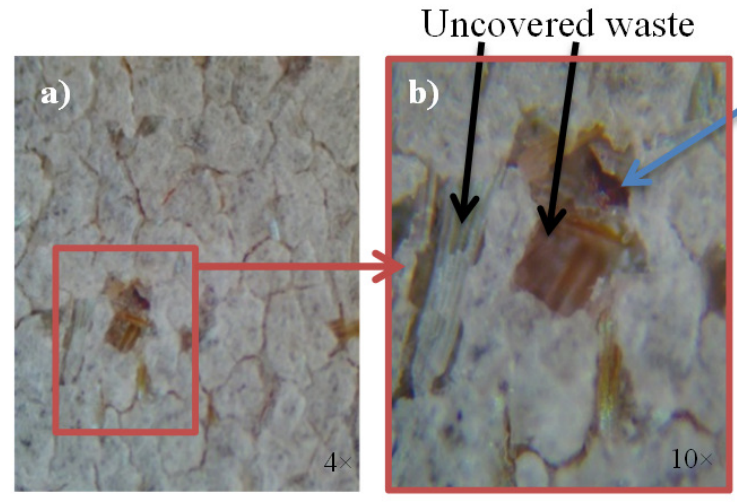

Fig.4. A40/(NaOH 0.05 \& TEOS 0.14:HF 1.6/2)/V/- composite surface after aging: $\mathrm{a}-4 \mathrm{x}$ magnification; $\mathrm{b}-10 \mathrm{x}$ magnification

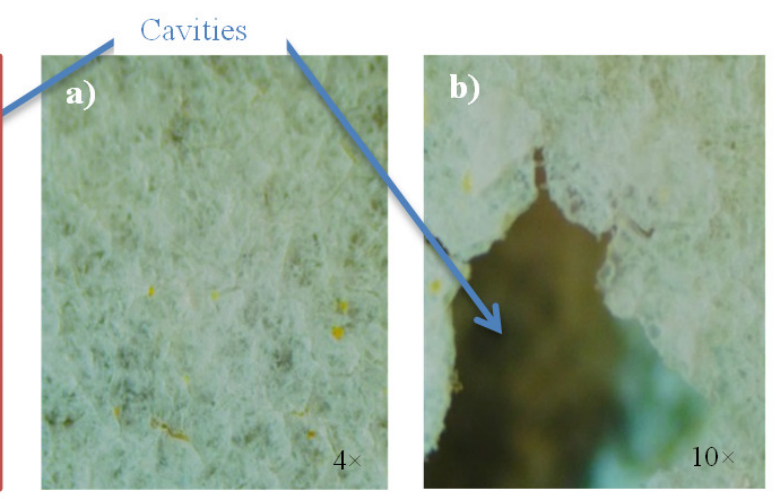

Fig.5. A40/(NaOH 0.05 \& TEOS 0.09:HF 0.8: ZAD 7.5/5.5)/V/- surface of composite after aging: $a-4 x$ magnification; $b-10 x$ magnification

\section{Composite cross-section analysis}

The pressed composite thickness before ageing was $1 \mathrm{~mm}$. Untreated waste composite footprint of ageing was observed at the depth of $0.23 \mathrm{~mm}$. Similar results were observed for the composite with alkali waste treatment combined with $\mathrm{ZnO}$ nanoparticle additive $-0.24 \mathrm{~mm}$. For the composites with waste treated with APTES sol was $0.22 \mathrm{~mm}$ and silanized - $0.25 \mathrm{~mm}$ (Fig. 6).

Ageing of composites with MAPE additive $(0.36 \mathrm{~mm})$ and $\mathrm{NaOH}$ waste treatment $(0.27 \mathrm{~mm})$ was faster than of the untreated waste composite. The addition of maleic anhydride to the composite processing causes faster ageing and a decrease in the mechanical properties, which is confirmed by other studies [9]. The effects of treating cannabis with alkali in literature vary depending on the temperature used, the alkali concentration and the chemical composition of cannabis, as lignin and hemicelluloses are removed $[14 ; 10]$.

Smaller footprint of ageing was found on the composites with waste treated with ZAD-containing sols or treated with TEOS $(0.18-0.19 \mathrm{~mm})$. The aged part of $1 \mathrm{~mm}$ thick sample could be seen in about a quarter of the total sample thickness, suggesting that the mechanical properties need to be re-tested after ageing. To summarize the cross-section aged layer depth of the composites, the waste treated with sol-gel treatment shows (4-22\%) better resistance to ageing than the reference sample and other treatments.

The SEM micrographs of the $40 \mathrm{wt} \%$ untreated waste composite show deformation of the elastic matrix as a result of cutting the sample. Cracks were slightly visible on the composite surface, but it was not possible to detect damage at deeper layers. Next to image c, obtained with an optical microscope, it was easier to distinguish the aged layer, it is lighter than the other part of the composite and was extended up to a quarter of the total $\sim 1 \mathrm{~mm}$ thick sample. Both the aged and the unaged sides had visible ends of the hemp particles, which were pierced through the matrix, (Fig. 7).

The alkali-treated waste composite aged layer was smooth (Fig. 8), but $\mathrm{ZnO}$ additive affects the homogeneity of the aged layer, the large surface area of the nanoparticle additive reduces the possibility to evenly cover waste into the polymer matrix. The anti-UV properties of $\mathrm{ZnO}$ have also been confirmed by several publications $[15 ; 16]$, but it is necessary to reduce the amount of the additive. 


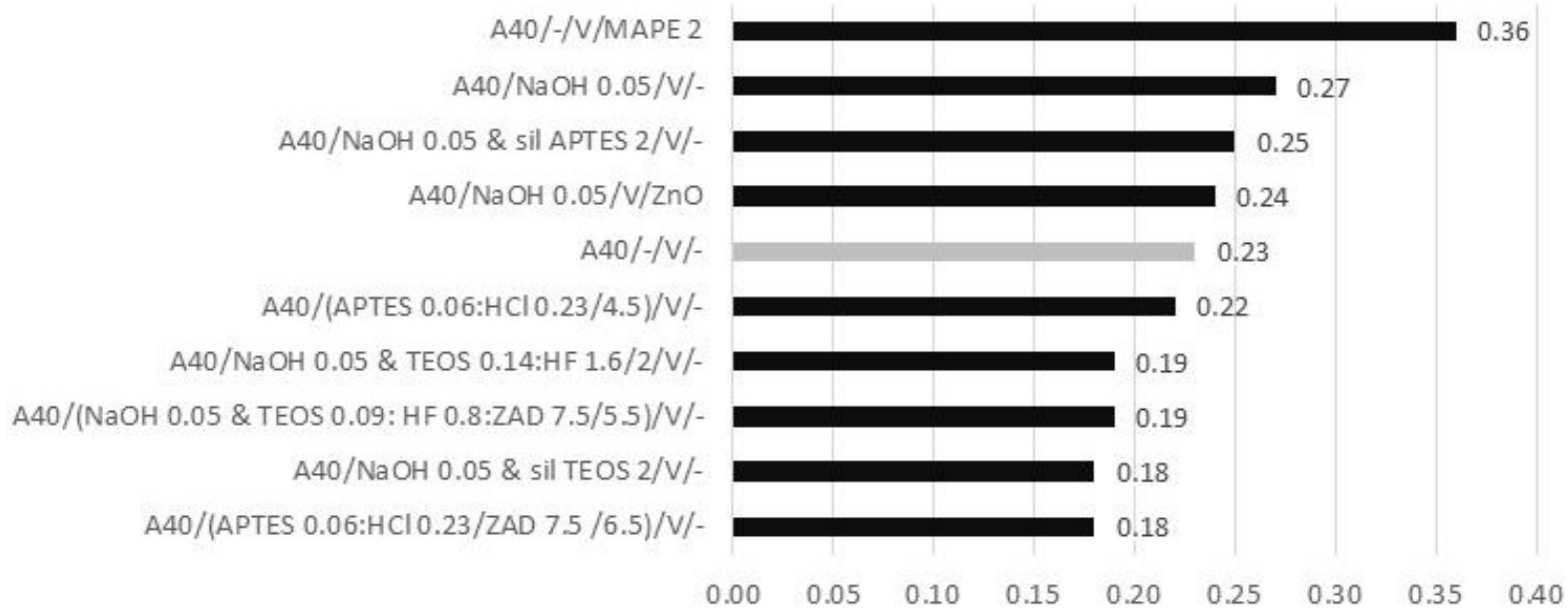

Fig. 6. Depth of aged layer of composite, $\mathbf{m m}$
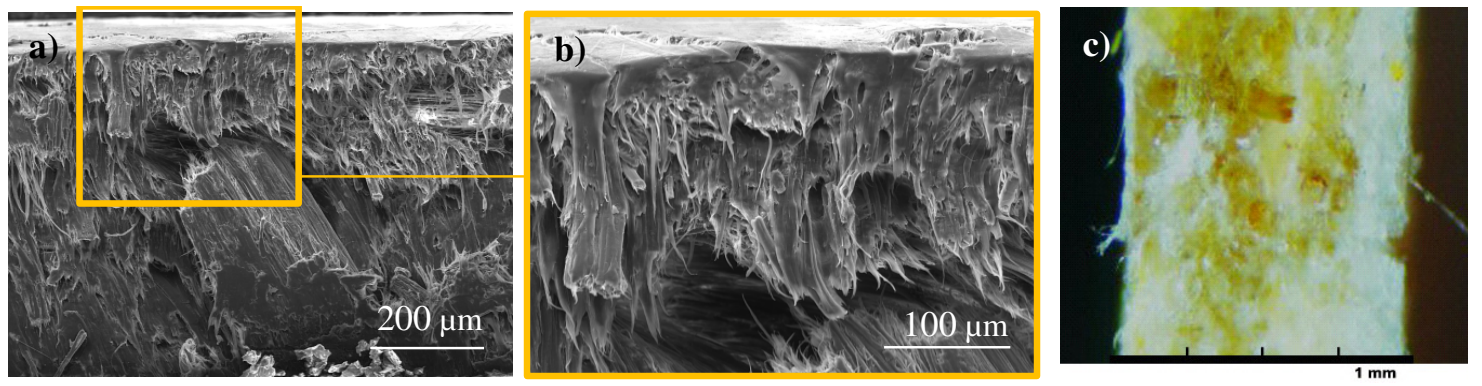

Fig. 7. Cross-section of LLDPE composites reinforced with untreated waste after aging: $\mathrm{a}$ and $\mathrm{b}-$ SEM micrograph (top part was aged); $\mathrm{c}-4 \mathrm{x}$ magnification optical image

(aged layer to the right) [13]
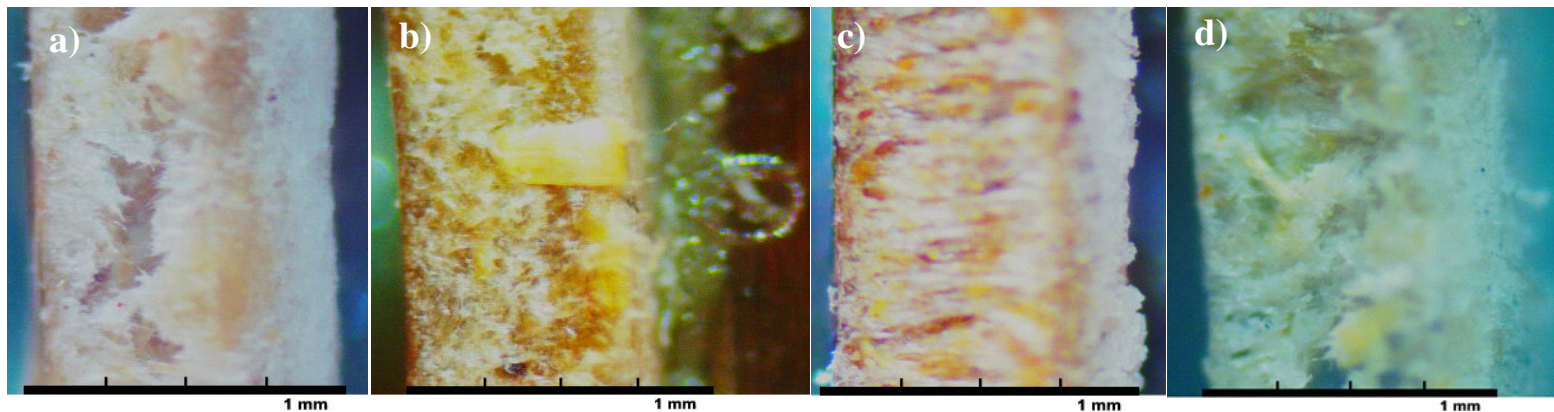

Fig. 8. Composite cross-section after aging at $4 \times$ magnification (aged composite part to the right): a - A40/(NaOH 0.05)/V/-; b - A40/-/V/MAPE 2 [13]; c - A40/(NaOH 0.05 \& TEOS 0.14:HF $1.6 / 2) / \mathrm{V} /-; \mathrm{d}-\mathrm{A} 40 /(\mathrm{NaOH} 0.05) / \mathrm{V} / \mathrm{ZnO}$

Under UV radiation, destruction of lignin has begun [17] and has increased colour changes. The composite where the waste was treated with TEOS 0.14: HF 1.6/2 sol, was thinner, but the flakes in the ageing chamber may have already been rinsed. After ageing, the composite A40/-/V/MAPE 2 was rapidly thinner, with reinforcing components protruding from its surface, the ageing layer being deeper than in the other samples (Fig. 8). The aged composite A40/(NaOH 0.05 \& TEOS 0.09:HF 0.8: ZAD 7.5/5.5)/V/- did not look as smooth as the others, (Fig. 9).

The composites with waste treated with APTES-containing sol modified by ZAD had a thinner aged layer (Fig. 9). Comparing both aged samples with the silanized waste, it can be seen that the APTES-treated waste sample has a smoother layer and the TEOS-aged composite - a deeper and looser layer. 

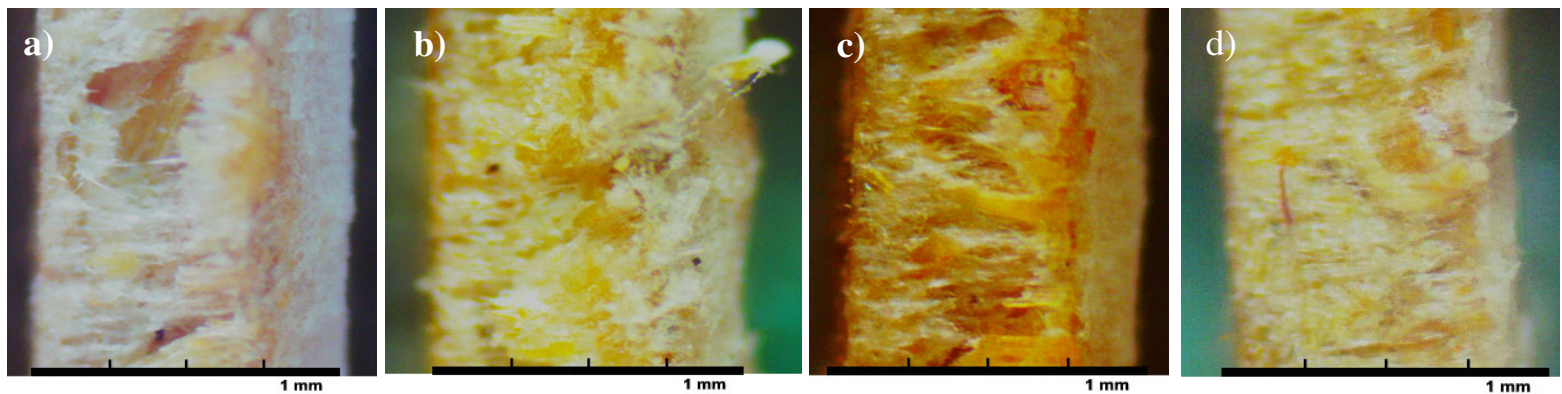

Fig. 9. Composite cross-sectional surface after ageing at $4 \times$ magnification (aged composite surfaces to the right): $\mathrm{a}-\mathrm{A} 40 /(\mathrm{NaOH} 0.05 \&$ sil APTES 2$) / \mathrm{V} /-; \mathrm{b}-\mathrm{A} 40 /(\mathrm{NaOH} 0.05 \&$ sil TEOS 2)/V/-; c - A40/(APTES 0.06:HCl 0.23/ZAD 7.5/6.5)/V/-; d - A40/(NaOH 0.05 \& TEOS 0.09:HF $0.8: \mathrm{ZAD} 7.5 / 5.5) / \mathrm{V} /-$

\section{Conclusions}

Ageing affects not only the layer of the polymer matrix, but also the reinforcing components. The selected ageing standard ASTM G154 was aggressive enough to predict the destruction of composites in outdoor environment after a period of approximately 2 to 3 years. Air inclusions occur during the composite manufacturing process. Exposing these air inclusions leads to faster destruction, so it is important to protect the surface directly. Composite finishes (stabilization) are required to prevent composites from being destroyed outdoors. The micro-hardness of the composite surface after ageing was decreased between 31 and $62 \%$. Comparing all the obtained composite images, the structure of the aged surface looks similar, the only exception was the composite A40/(NaOH 0.05 \& TEOS $0.14: \mathrm{HF} 1.6 / 2$ )/V/- sample surface with more pronounced cracks, the flakes were easily detached by touching. The aged part of $1 \mathrm{~mm}$ thick samples could be seen in about a quarter of the total sample thickness for all composites. Exposed cavities and cracks on the surface are signs that the mechanical properties like the tensile strength of the composites may have decreased and testing is required.

\section{Acknowledgements}

This research/publication was supported by the Riga Technical University Doctoral Grant programme.

\section{References}

[1] Strong B. A. Plastics: Materials and Processing. Prentice Hall, New Jersey, 2000. 811 p.

[2] Mahzan S., Fitri M., Zaleha M. UV radiation effect towards mechanical properties of Natural Fibre Reinforced Composite material: A Review. IOP Conf. Series: Materials Science and Engineering, vol. 165, 2017, pp. 1-9.

[3] Van Krevelen D. W., Nijenhuis K. T. Properties of Polymer. Netherland, Amsterdam: Elsevier Science, 2009. $1030 \mathrm{p}$.

[4] Zhang X. H. Manufacturing of Hemp/PP. Composites and Study of its Residual. Stress and Aging Behavior. PhD Thesis. Troyes: [UTT], 2016. 172 p.

[5] Nabinejad O., Sujan D., Rahman M. E., Ian J. D. Effect of oil palm shell powder on the mechanical performance and thermal stability of polyester composites. Materials and Design, vol. 65, 2015, pp. 823-830.

[6] Thyavihalli Girijappa Y.G., Mavinkere Rangappa S., Parameswaranpillai J., Siengchin S. Natural Fibres as Sustainable and Renewable Resource for Development of Eco-Friendly Composites: A Comprehensive Review. Frontiers and Materials, vol.6, 2019, 226 p.

[7] Ching Y. C., Gunathilake TMS U., Ching K. Y., Chuah C. H., Sandu V., Singh R., Liou N. Effects of High Temperature and Ultraviolet radiation on Polymer Composites. Durability and Life Prediction in Biocomposites, Fibre-Reinforced Composites and Hybrid Composites. Woodhead Publishing Series in Composites Science and Engineering. Elsevier Ltd. 2019, pp. 407-426.

[8] Azwa Z. N., Yousif B. F., Manalo A. C., Karunasena W. A review on the degradability of polymeric composites base on natural fibres. Materials and Design, vol.47, 2013, pp. 424-442. 
[9] Joseph P. V., Rabello M. S., Mattoso L. H. C., Joseph K., Thomas S. Environmental effects on the degradation behaviour of sisal fibre reinforced polypropylene composites. Composite Science and Technology, vol.62, 2002, pp. 1357-1372.

[10] Lu N., Oza S. A comparative study of the mechanical properties of hemp fiber with virgin and recycled high density polyethylene matrix. Composites Part B Engineering, vol.45, 2013, pp. 1651-1656.

[11] ASTM G154 - 16. Standard Practice for Operating Fluorescent Ultraviolet (UV) Lamp Apparatus for Exposure of Nonmetallic Materials.

[12] ASTM E384 Standard Test Method for Microindentation Hardness of Materials.

[13]Zelča Z. Extension of Assortment of Hemp-Based Composite and Technology Optimization. PhD Thesis. Rìga: [RTU], 2019. 163 p.

[14]Zhang H., Zhong Z., Feng L. Advances in the Performance and Application of Hemp Fiber. International Journal of Simulation Systems, Science \& Technology, vol.17, 2016, pp. 18.1-18.5.

[15]Liu J., Wang Y., Ma J., Peng Y., Wang A. A Review on Bidirectional Analogies Between the Photocatalysis and Antibacterial Properties of ZnO. Applied Surface Science, vol. 469, 2019, pp. 204 - 212.

[16] Nasouri K. Fabrication of lightweight and flexible cellulose acetate composite nanofibers for high-performance ultraviolet protective materials. Polymer Composites, vol.40, 2019, pp. 33253332.

[17] Cogulet A., Blanchet P., Landry V. Wood degradation under UV irradiation: A lignin characterization. Journal of photochemistry and photobiology. B, Biology vol.158, 2016, pp. 184191. 